\title{
Avaliação patológica do nível de deterioração de estruturas de concreto armado de edificações públicas de ensino - estudo de caso.
}

\author{
B. M. G. M. P. Moya'*, D. A. Silva', A. Frare² \\ *Autor de Contato: beatrixmmaia@gmail.com \\ ${ }^{1}$ Coordenação do Curso de Engenharia Civil, Universidade Tecnológica Federal do Paraná - UTFPR, Guarapuava, \\ Paraná, Brasil \\ ${ }^{2}$ Pesquisadora, Universidade Federal do Paraná - UFPR, Curitiba, Paraná, Brasil
}

\begin{abstract}
RESUMO
O estudo avalia as manifestações patológica encontradas em estruturas de concreto armado de 11 edificações pública de uso para o ensino. A metodologia utilizada para caracterizar e analisar os tipos de patologia, nesta edificação, foi a que estima o Grau de Deterioração de Estruturas (GDE), a qual faz uso de fórmulas e organização dos dados coletados em campo. $\mathrm{O}$ estudo de caso se desenvolveu através de vistoria in loco dos elementos estruturais das edificações, classificadas em blocos, e registro fotográfico das mesmas; posteriormente, foram analisados os elementos que apresentaram patologia e determinado quais eram seus graus de deterioração. Através deste estudo foi possível observar quais as principais patologia e ocorrências que foram encontradas nestas edificações, destacando-se as manchas $(29,0 \%)$; umidades $(28,5 \%)$; fissuras $(25,5 \%)$ e outras patologia (17\%), as quais incluem flechas, eflorescências, carbonatações, corrosões, cobrimentos insuficientes e segregações.
\end{abstract}

Palavras chave: Patologia das Estruturas; Concreto Armado; Metodologia GDE/UnB. 


\title{
Pathological assessment of the level of deterioration of reinforced concrete structures in public teaching buildings - case study.
}

\begin{abstract}
The study evaluates the pathological manifestations found in reinforced concrete structures in 11 public buildings used for teaching purposes. The methodology used to characterize and analyze the types of pathology in this building was the one that estimates the Degree of Deterioration of Structures (GDE), which makes use of formulas and organization of data collected in the field. The case study was developed through an in loco inspection of the structural elements of the buildings, classified in blocks, and photographic record of the same; subsequently, the elements that presented pathology were analyzed and their degrees of deterioration were determined. Through this study, it was possible to observe the main pathology and occurrences that were found in these buildings, highlighting the spots $(29.0 \%)$; humidity $(28.5 \%)$; cracks $(25.5 \%)$ and other pathologies $(17 \%)$, which include arrows, efflorescence, carbonation, corrosion, insufficient coverage and segregation.
\end{abstract}

Keywords: Structural pathologie; Reinforced Concrete; Methodology GDE / UnB.

\section{Evaluación patológica del nivel de deterioro de estructuras de hormigón armado en edificios públicos de enseñanza - estudio de caso.}

\section{RESUMEN}

El estudio evalúa las manifestaciones patológicas encontradas en estructuras de hormigón armado en 11 edificios públicos destinados a la docencia. La metodología utilizada para caracterizar y analizar los tipos de patología en este edificio fue la que estima el Grado de Deterioro de Estructuras (DEG), que hace uso de fórmulas y organización de los datos recolectados en campo. El estudio de caso se desarrolló mediante una inspección in loco de los elementos estructurales de los edificios, clasificados en bloques, y registro fotográfico de los mismos; Posteriormente, se analizaron los elementos que presentaban patología y se determinaron sus grados de deterioro. A través de este estudio, fue posible observar las principales patologías y ocurrencias que se encontraron en estos edificios, destacando las manchas (29,0\%); humedad (28,5\%); grietas $(25,5 \%)$ y otras patología (17\%), que incluyen flechas, eflorescencias, carbonatación, corrosión, cobertura insuficiente y segregación.

Palabras clave: Patología estructurales; Hormigón armado; Metodología GDE / UnB.

\section{INTRODUCÃO}

A patologia é um dos principais fatores que afetam a vida útil e durabilidade das estruturas, sendo, portanto, muito preocupante para as construções civis. Esses conceitos só foram abordados no Brasil a partir de 2003, com a inclusão da classificação quanto a agressividades na ABNT NBR 6118 (2003), onde a partir de então começaram a se preocupar com a qualidade do concreto e também do cobrimento da armadura. Antes desse período, as obras em estruturas de concreto armado não tinham essa preocupação quanto a esses aspectos, como a deterioração do concreto. 
Devido a isto, muitas obras brasileiras, com 25 anos ou 18 mais, irão atingir precocemente sua vida útil de projeto e de serviço, e já apresentam patologia severas (BORDUN, 2014).

Em função disso, o setor da Construção Civil está se voltando a uma tendência mundial no sentido de privilegiar os aspectos de projeto voltados à durabilidade e a expansão da vida útil das estruturas de concreto armado e, também, protendido (MEDEIROS; ANDRADE; HELENE, 2011).

Entretanto, devido a problemas ainda existentes no Brasil em relação a projeto, execução e/ou manutenção, os investimentos necessários para os reparos e manutenções das estruturas ainda é muito significativo (MEHTA; MONTEIRO, 1994).

Por isso, é de extrema importância o diagnóstico precoce da patologia existentes nas construções civis. Esse diagnóstico pode ser obtido por meio de diversas metodologias que demonstrem qual o grau de deterioração dos elementos que apresentem patologia, para realizar a devida manutenção e reparo. A Metodologia GDE/UnB é um exemplo de metodologia utilizada para este fim, a qual foi formulada por Castro em 1994, sendo posteriormente aprimorada e atualizada por outros autores.

A fim de identificar, caracterizar e analisar as principais manifestações patológica encontradas nas estruturas de concreto armado de um conjunto de edificações públicas, na cidade de Guarapuava no estado do Paraná-Brasil, este trabalho irá determinar o grau de deterioração destas estruturas de concreto armado, por meio da metodologia GDE/UnB para valoração e priorização de intervenções a fim de aumentar a durabilidade e vida útil da estrutura.

\section{ASPECTOS GERAIS SOBRE A METODOLOGIA GDE/UNB}

A metodologia GDE, cujo significado é Grau de Deterioração de Estruturas, teve sua origem em um Programa de mestrado em Estruturas e Construção Civil na Universidade de Brasília (PECCUnB). Tal metodologia foi desenvolvida por Castro em 1994, a fim de realizar uma avaliação quantitativa do grau de deterioração em estruturas de concreto armado em edificações usuais, visando estabelecer os danos e evoluções das manifestações patológicas que podem ocorrer nessas estruturas, avaliando o desempenho dos elementos estruturais de uma edificação nos aspectos de segurança, funcionalidade e estética desses e viabilizando quais são as prioridades para a realização das manutenções necessárias. Posteriormente, tal metodologia foi estudada e aprimorada por Lopes, em 1998, Boldo, em 2002, Fonseca, em 2007, Euqueres, em 2011 e Verly, em 2015 (BOAS, et al., 2018).

Em 1994, Castro, assim que aplicou esta metodologia, logo percebeu que existia uma necessidade de um número maior de aplicações, para que as fórmulas e parâmetros empregados tivessem uma melhor determinação do grau dessas manifestações. Para isso, foi criado um Caderno de Inspeções, o qual abrangia a concepção dos danos de maior incidência em cada grupo de elementos, chamados de famílias, e determinava um Fator de Intensidade do dano (Fi), a fim de facilitar os trabalhos de inspeções em estruturas de concreto armado.

Entretanto, através de estudos e aplicações da metodologia criada por Castro, foi comprovado que os cálculos realizados poderiam levar a resultados desconexos. Então, em 1998, Lopes modificou essa metodologia, alterando a fórmula do grau de deterioração do elemento, conhecida, desde Castro, por Gde.

Com o intuito de sempre melhorar a metodologia para quantificar as manifestações patológicas, Boldo, em 2002, realizou estudos para que, através do princípio já estudado por Lopes, fosse possível determinar o grau de deterioração da família dos elementos (Gdf) em edificações de concreto armado com diferentes finalidades de ocupação, e, com isso, alterou a denominação do Caderno de Inspeções para Inspeção para Estruturas de Concreto.

Posteriormente, em 2007, Fonseca apresentou alteração em algumas fórmulas utilizadas na metodologia GDE/UnB, como a fórmula para cálculo do Grau de deterioração da família (Gdf) e a 
fórmula do Grau do Dano (D), além de apresentar uma alteração nos tipos de patologia mais frequentes que podem ocorrer em estruturas de concreto armado.

Euqueres e Verly adaptaram a metodologia GDE/UnB, que era apenas utilizada em edificações de concreto armado, para utilizá-la em estruturas de pontes e estruturas de viadutos, respectivamente, nos anos de 2011 e 2015, respectivamente. Além disso, Euqueres também realizou uma modificação no antigo nome dado como Roteiro de Inspeção para Estruturas e Pontes de Concreto armado, a fim de ficar

contextualizado no novo tema que abordaria com a metodologia. E Verly, realizou algumas modificações na formulação do grau de deterioração das estruturas (Gd), além de criar um material, denominado como Manual de Aplicação da Metodologia GDE/UnB a Obras de Arte Especiais.

Desta forma, é possível compreender que a metodologia GDE/UnB, apesar de ter sido criada para avaliação quantitativa de manifestações patológicas em edificações em concreto armado, pode, também, ser utilizada e aplicada em outros modelos de estruturas, através de inspeções e análises, avaliando tanto o elemento isolado quanto no todo. Além disso, essa metodologia também pode ter uma utilidade para manutenções corretivas, analisando os elementos com falhas de maior gravidade e/ou urgência, e concluindo qual deverá ter prioridade, tomando como base o âmbito técnicofinanceiro dessas intervenções.

De acordo com Fonseca (2007), a forma de utilização dessa metodologia deve seguir os passos esquematizados em um fluxograma criado por Castro em 1994, o qual apresenta uma sequência dos procedimentos bem definidos, que facilita sua aplicação pelo inspetor da patologia.

A Figura 1 demonstra, de forma sistemática, o roteiro a ser seguido na sua aplicação, onde cada uma dessas etapas será genericamente apresentada a seguir, definindo todos os parâmetros utilizados.

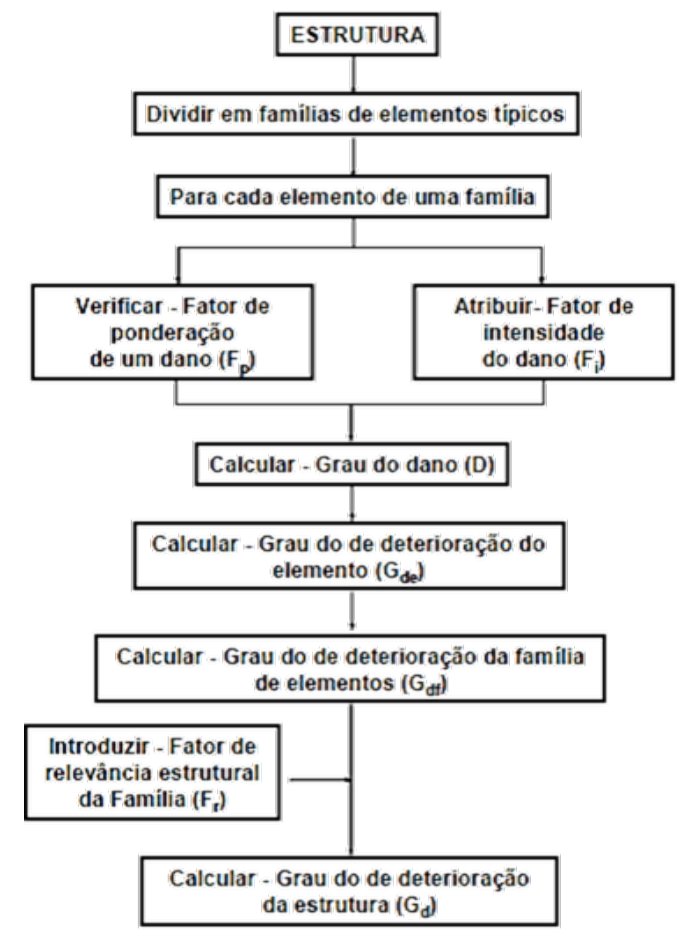

Figura 1- Fluxograma da metodologia GDE/UnB

A seguir será descrita cada etapa da metodologia GDE/UnB, de acordo com as modificações realizadas por Fonseca, em 2007, e posteriormente, quais as fórmulas utilizadas e como proceder com cada uma. 


\subsection{Divisão em famílias de elementos}

A divisão em famílias de elementos ocorre através de um agrupamento de elementos, com funcionalidades características, da edificação, sendo divididas nas seguintes famílias:

- Pilares;

- Vigas;

- Vigas secundárias;

- Lajes;

- Cortinas (muros de arrimo);

- Escadas/rampas;

- Reservatórios (inferiores e superiores);

- Blocos de fundação;

- Juntas de dilatação;

- Elementos de composição arquitetônica.

\subsection{Formulações da metodologia GDE/UnB}

\subsubsection{Grau de dano (D)}

O grau de dano $(D)$ de um elemento estrutural (lajes, pilares, vigas, etc.) foi proposto inicialmente por Tuutti em 1982 e generalizado pelo Código Modelo MC - 90 CEB-FIP em 1991, é calculado através dos fatores de ponderação $\left(F_{p}\right)$ e o fator de intensidade $\left(F_{i}\right)$, que leva em consideração a evolução da corrosão da armadura deste e para isto é necessário fazer uso de tabelas de referência estruturadas por Fonseca (2007). Seu cálculo é realizado conforme (1).

$$
\begin{array}{cc}
D=0,8 \cdot F_{i} \cdot F_{p} & \text { para } F_{i} \leq 2,5 \\
D=\left(12 \cdot F_{i}-28\right) \cdot F_{p} & \text { para } F_{i}>2,5
\end{array}
$$

Onde:

$F_{i}$ : Fator de intensidade do dano;

$F_{p}:$ Fator de ponderação do dano.

\subsubsection{Grau de deterioração de um elemento $\left(G_{d e}\right)$}

De acordo com Lopes (1988), o grau de deterioração de um elemento $\left(G_{d e}\right)$ é calculado através do grau do dano $(D)$, obtido através da (1). A obtenção do Gde se dá pela (2) a seguir.

$$
G_{d e}=D_{\text {máx }} \cdot\left[1+\frac{\sum_{i=1}^{m} D_{(i)}-D_{\text {máx }}}{\sum_{i=1}^{m} D_{(i)}}\right]
$$

Onde:

$D_{\text {máx }}$ : Maior grau de dano no elemento; 
$m$ : Número de danos detectados no elemento;

$D_{(i)}$ : O grau de dano de ordem (i).

Após o cálculo realizado através da (2), é possível determinar qual o nível de deterioração do elemento da estrutura estudado de acordo com o valor obtido do $G_{d e}$, e, com isso, adotar a ação necessária, a fim de prolongar a vida útil e a segurança deste elemento, conforme verificado através da Tabela 1.

Tabela 1 Classificação do nível de deterioração de determinado elemento da estrutura

\begin{tabular}{|c|c|c|}
\hline Nível de deterioração & $\mathbf{G}_{\text {de }}$ & Ações a serem adotadas \\
\hline Baixo & $0-15$ & Estado aceitável. Manutenção preventiva. \\
\hline Médio & $15-50$ & $\begin{array}{c}\text { Definir prazo/natureza para nova inspeção. Planejar intervenção } \\
\text { em longo prazo (máx. } 2 \text { anos) }\end{array}$ \\
\hline Alto & $50-80$ & $\begin{array}{l}\text { Definir prazo/natureza para inspeção especializada detalhada. } \\
\text { Planejar intervenção em médio prazo (máx. } 1 \text { ano) }\end{array}$ \\
\hline Sofrível & $80-100$ & $\begin{array}{l}\text { Definir prazo/natureza para inspeção especializada detalhada. } \\
\text { Planejar intervenção em curto prazo (máx. } 6 \text { meses) }\end{array}$ \\
\hline Crítico & $>100$ & Inspeção especial emergencial. Planejar intervenção imediata. \\
\hline
\end{tabular}

\subsubsection{Grau de deterioração de uma família de elementos $\left(G_{d f}\right)$}

Para o cálculo do grau de deterioração de uma família de elementos $\left(G_{d f}\right)$, seguindo os estudos realizados por Fonseca (2007), deve-se atentar primeiramente ao valor obtido com o grau de deterioração do elemento estrutural $\left(G_{d e}\right)$, que deve obter um valor médio ou superior, conforme Tabela 1 , ou seja, seu valor deve ser maior ou igual a 15 . O cálculo do $G_{d f}$, é realizado a partir da (3).

$$
G_{d f}=G_{d e_{\max }} \cdot\left[\sqrt{1+\frac{\sum_{i=1}^{m} G_{d e_{(i)}}-G_{d e_{\max }}}{\sum_{i=1}^{m} G_{d e_{(i)}}}}\right]
$$

Onde:

$G_{d f_{\text {máx }}}$ : Grau de deterioração máxima do elemento;

$G_{d f_{(i)}}$ : Grau de deterioração do elemento de ordem (i).

\subsubsection{Fator de relevância estrutural $(F r)$}

O último fator considerado para cálculo do grau de deterioração da estrutura $\left(G_{d}\right)$ é o fator de relevância estrutural $\left(F_{r}\right)$, o qual, de acordo com Moreira (2007), tem por objetivo considerar a 
importância relativa das diversas famílias que subdividem a estrutura quanto ao seu comportamento e desempenho. Esse fator varia de 1 a 5, e seu valor é correspondente a família que faz parte, conforme apresentado na Tabela 2 .

Tabela 2 Fatores de relevância estrutural

\begin{tabular}{cc}
\hline Famílias em conjunto & Fatores de relevância estrutural $\left(\boldsymbol{F}_{\boldsymbol{r}}\right)$ \\
\hline Elementos de composição arquitetônica & 1 \\
Reservatório superior & 2 \\
Escadas/rampas, reservatório inferior, cortinas, lajes \\
secundárias e juntas de dilatação \\
Lajes, fundações, vigas secundárias e pilares secundários \\
Vigas e pilares principais
\end{tabular}

\subsubsection{Grau de deterioração da estrutura $\left(G_{d}\right)$}

A fim de conhecer qual o grau de deterioração de uma determinada estrutura, é necessário o conhecimento do fator de relevância de cada família, conforme especificado na Tabela 2, e o grau de deterioração da família, estipulado conforme (3). Após isso, aplica-se esses valores na (4) para obter qual o grau de deterioração global da estrutura $\left(G_{d}\right)$.

$$
G_{d}=\frac{\sum_{i=1}^{K} F_{r(i)} \cdot G_{d f(i)}}{\sum F_{r(i)}}
$$

Onde:

$K$ : Número de famílias de elementos presentes na edificação;

De maneira semelhante ao que ocorre com o grau de deterioração do elemento $\left(G_{d e}\right)$, faz-se com o grau de deterioração global da estrutura $\left(G_{d}\right)$ também, aplicando a intervenção necessária na estrutural conforme valor estipulado pela (4) e através da Tabela 3 estipula a melhor ação a ser adotada.

Tabela 3 Classificação do nível de deterioração global da estrutura

Nível de deterioração $\quad G_{d} \quad$ Ações a serem adotadas


Baixo $\quad 0-15 \quad$ Estado aceitável. Manutenção preventiva.

Médio $\quad 15-50$ Definir prazo/natureza para nova inspeção. Planejar intervenção em longo prazo (máx. 2 anos)

Alto $\quad 50-80 \quad$ Definir prazo/natureza para inspeção especializada detalhada. Planejar intervenção em médio prazo (máx. 1 ano)

Sofrível $80-100$ Definir prazo/natureza para inspeção especializada detalhada. Planejar intervenção em curto prazo (máx. 6 meses)

\section{CARACTERIZAÇÃO DO LOCAL DE ESTUDO}

As atividades da instituição de ensino tiveram início na cidade de Guarapuava no ano de 2011, porém ainda não eram exercidas no seu câmpus. Apenas em 2014 que as aulas começaram a serem desenvolvidas em sua sede própria, a qual está inserida em uma infraestrutura com área total de $7000 \mathrm{~m}^{2}$, subdividida atualmente em 11 blocos. A instituição de ensino está sinalizada com o marcador em vermelho conforme Figura 2. A sua localização é em um bairro que está em implantação, o qual oferece, além da universidade, supermercados, shopping, hospital regional, dentre outras edificações de moradia e comércio que ainda se encontram em construção.

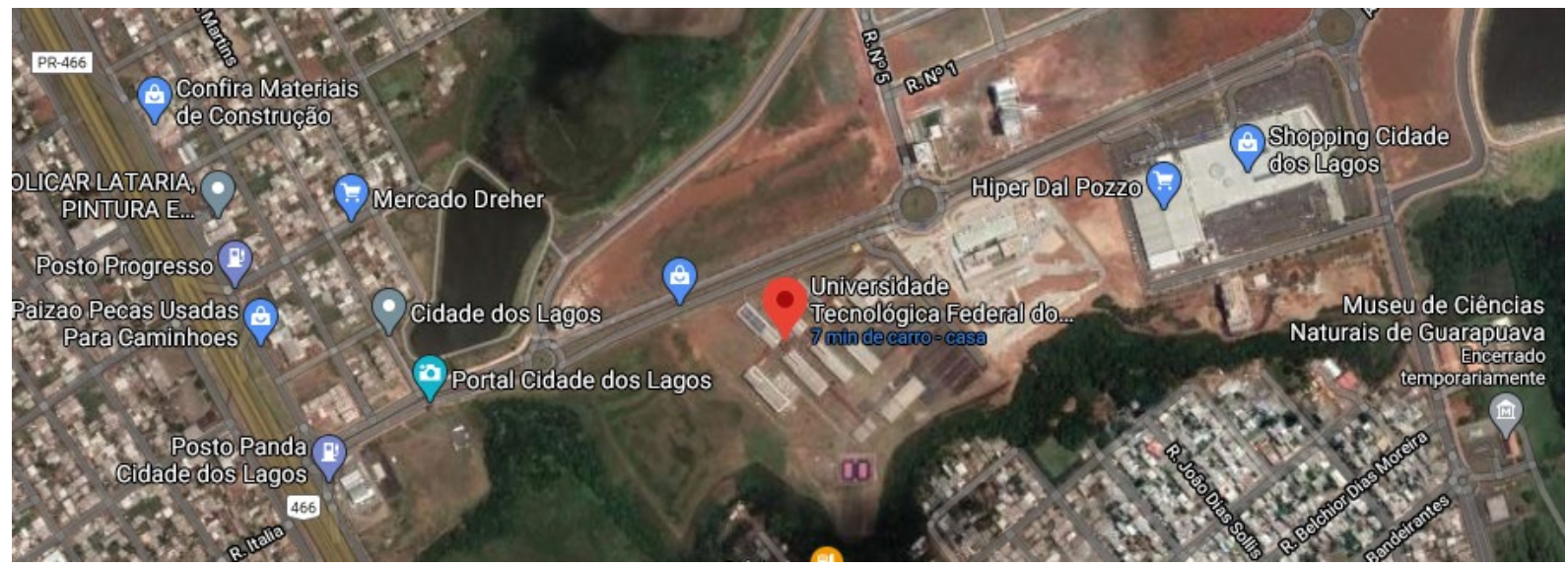

Figura 2 Localização da UTFPR - Câmpus Guarapuava Fonte: Google Earth (acesso em 08 abr. 2021)

Na Figura 3 é apresentado como é feita a distribuição dos onze blocos presentes na instituição de ensino. Esses blocos são nomeados a partir de letras do alfabeto romano. Os blocos A, B, C, D, E, F e H são utilizados para as aulas teóricas e práticas, e é onde estão localizadas as salas dos professores. O bloco P é direcionado para garagem dos carros oficiais, oficina, depósito e cantina para funcionários e terceirizados. $\mathrm{O}$ bloco $\mathrm{O}$ é utilizado para servir as refeições do restaurante universitário, conhecido como RU. O bloco R é utilizado para recepção na universidade e também administrativo. E o bloco S é onde localiza-se o teatro da instituição de ensino. 


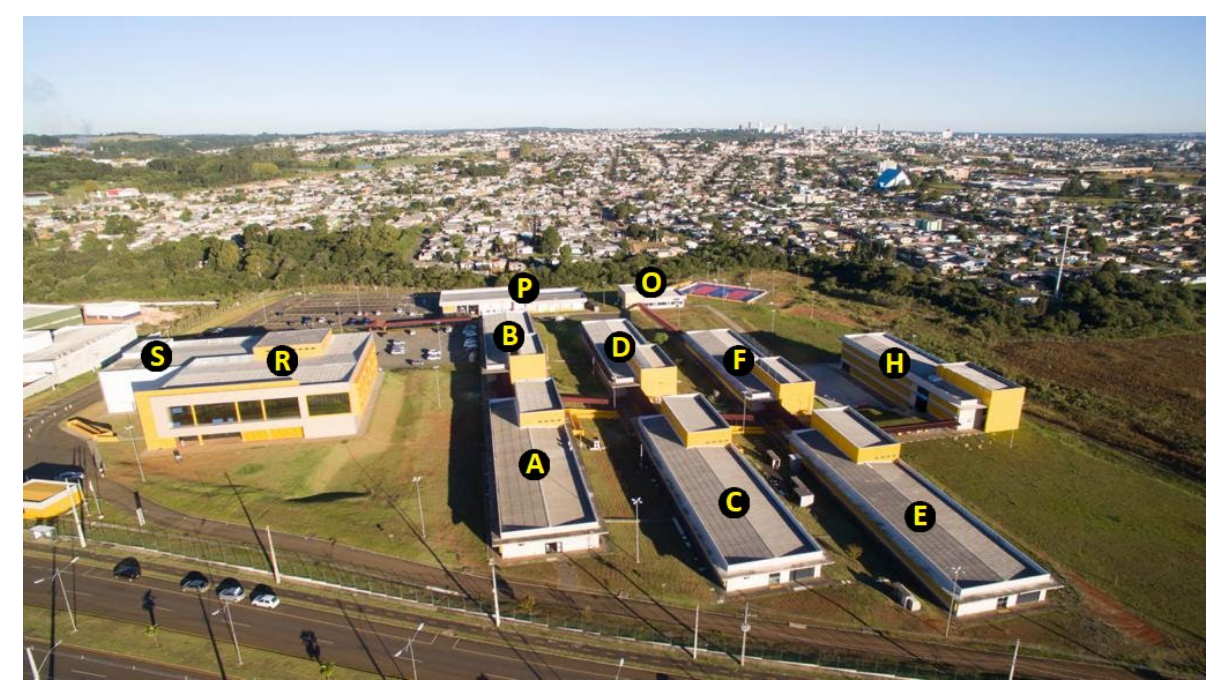

Figura 3 Disposição dos blocos da UTFPR - câmpus Guarapuava

O estudo do grau de deterioração das estruturas de concreto armado da instituição de ensino será realizado em todos seus onze blocos, apresentados pela Figura 3, utilizando a versão mais recente da Metodologia GDE/UnB, a qual foi reformulada por Fonseca em 2007. A classe de agressividade ambiental destas estruturas é dada como moderada, devido ao fato da instituição de ensino encontrar-se em ambiente urbano.

Inicialmente será necessária uma representação gráfica dos blocos que serão estudados, para obter uma localização e identificação precisa da patologia. Para isso, serão utilizados croquis do projeto estrutural de cada um dos blocos, os quais possuem elementos estruturais especificados, como as lajes, vigas, marquises, pilares e escadas. Com esses croquis, será possível denominar, através de vistoria in loco, em quais elementos existem patologia (pilares, vigas, lajes, escadas e marquises), quais seus tipos e determinar qual seu fator de ponderação e o fator de intensidade, para cálculo do grau de deterioração desses elementos. Além disso, serão registrados, através de fotografias, as principais manifestações patológicas para registro. $\mathrm{O}$ acesso à cobertura dos blocos não foi possível, exceto no bloco R e $\mathrm{S}$, não sendo estudadas a patologia que poderiam estar presentes nestes locais.

Para a patologia de fissura, será necessário identificar em qual classificação elas se encontram, sendo essas: fissura, trinca, rachadura e fenda. Essa classificação ocorre de acordo com sua espessura, as quais serão medidas com auxílio de um fissurômetro e paquímetro, quando necessário e possível acesso. O fator de ponderação das fissuras é classificado de forma precisa, devido a sua análise ser mais minuciosa, sendo determinado conforme proposto Fonseca (2007). Além dos instrumentos citados anteriormente, também será utilizada a fenolftaleína, que é um composto orgânico utilizado para verificação de carbonatação em estruturas de concreto armado. Após isso, será determinado em cada um desses elementos, de cada um dos blocos da universidade, qual é o seu grau de deterioração, para, posteriormente, poder determinar o grau de deterioração da família de elementos de cada um desses blocos, conforme designado pelo fluxograma da Figura 1e as formulações apresentadas.

O cálculo do grau de deterioração dos elementos e das famílias serão realizados através de planilhas criadas com auxílio do software Excel , para cada elemento, qual seu fator de ponderação, fator de intensidade, grau de dano $(D)$ através da (1) e grau de deterioração do elemento $\left(G_{d e}\right)$ através da (2), após isso será realizado o cálculo do grau de deterioração da família desses elementos $\left(G_{d f}\right)$ 
através da (3), subdivididos em pilares, vigas, lajes e escadas, o fator de relevância estrutural $\left(F_{r}\right)$ de cada uma das famílias especificado na Tabela 2. O grau de deterioração global do bloco em estudo, calculado através da (4), será apresentado em um quadro separado.

\section{ANÁLISE E DISCUSSÃO DOS RESULTADOS}

Aplicando-se o grau de deterioração global da estrutura $\left(G_{d}\right)$, é possível classificar os blocos com falhas de maior gravidade e/ou urgência de manutenções corretivas conforme Tabela 4, e concluir que o bloco F, seguido do bloco B e H, são os que deverão ter prioridade, com isto justificam os investimentos necessários.

Tabela 4 Prioridades de manutenção em função do Grau de Deterioração $\left(G_{d}\right)$ dos blocos.

\begin{tabular}{ccc}
\hline BLOCO & Gd & PRIORIDADE DE INTERVENÇÃO \\
\hline F & 71 & $\mathbf{1}$ \\
B & 66 & $\mathbf{2}$ \\
H & 46 & $\mathbf{3}$ \\
P & 44 & $\mathbf{4}$ \\
D & 42 & $\mathbf{5}$ \\
C & 38 & $\mathbf{6}$ \\
E & 38 & $\mathbf{7}$ \\
R & 38 & $\mathbf{8}$ \\
A & 15,71 & $\mathbf{9}$ \\
S & 6 & $\mathbf{1 0}$ \\
O & 5 & $\mathbf{1 1}$ \\
\hline \hline
\end{tabular}

Nestes blocos, esse tipo de patologia é verificado nos diversos elementos estruturais de concreto armado, sendo distribuído, conforme Tabela 5. Desta forma, é possível entender que a patologia que ocorrem nas edificações, encontram-se mais contundente ao surgimento da seguinte forma: nas lajes, vigas e seguidas de pilares. Esta ordem vem de acordo com o estudo de Mazer (2008), apenas variando o percentual da distribuição da patologia nos elementos estruturais.

Tabela 5 Percentual das distribuições das principais causas de patologia nos elementos estruturais

\begin{tabular}{cccccc}
\hline Elementos estruturais & Lajes & Vigas & Pilar & Marquises & Escadas \\
\hline Presente & $48,0 \%$ & $25,5 \%$ & $25,0 \%$ & - & $1,5 \%$ \\
Mazer (2008) & $60 \%$ & $23 \%$ & $7 \%$ & $10 \%$ & - \\
\hline \hline
\end{tabular}

Foram identificadas um total de 200 ocorrências de patologia dentre os diversos elementos de concreto existentes, conforme Tabela 6.

Tabela 6 Caracterização das recorrências de patologia na UTFPR - câmpus Guarapuava 


$\begin{array}{ccc}\text { Mancha } & 58 & 29,00 \% \\ \text { Umidade } & 57 & 28,50 \% \\ \text { Fissura } & 51 & 25,50 \% \\ \text { Flecha } & 11 & 5,50 \% \\ \text { Eflorescência } & 16 & 8,00 \% \\ \text { Outros (Carbonatação, Corrosão, Cobrimento e Segregação) } & 5 & 2,50 \% \\ \text { Desplacamento } & 2 & 1,00 \% \\ \text { Total } & 200 & 100 \%\end{array}$

Dentre as manifestações patológica registradas, as que se apresentaram majoritariamente foram: umidade, mancha e fissura, com uma incidência de 57, 58 e 51 ocorrências, respectivamente. Para prevenir que essas manifestações patológicas aumentem, é recomendado que seja realizada terapias para recuperação dos elementos que as apresentam. A Tabela 7 demonstra, de forma resumida, as principais manifestações patológica encontradas nas edificações, quais as suas possíveis causas, suas origens, qual o mecanismo destas e quais as correções que devem ocorrer para prosperar a durabilidade e vida útil dessas estruturas, prezando pelo custo das manutenções, devendo sempre ser realizado um preparo inicial correto da superfície.

Tabela 7 Causas, origens, mecanismos e correções

\begin{tabular}{|c|c|c|c|c|}
\hline $\begin{array}{c}\text { Manifestação } \\
\text { Patológica }\end{array}$ & Causa & Origem & Mecanismo & Correçães \\
\hline Umidade & $\begin{array}{c}\text { Prorosidade e rugosidade do } \\
\text { concreto }\end{array}$ & $\begin{array}{c}\text { Projeto } \\
\text { Execução } \\
\text { Materiais } \\
\text { Utilização }\end{array}$ & $\begin{array}{c}\text { Infiltração da água } \\
\text { e aparecimento de } \\
\text { pequenas ou } \\
\text { grandes manchas } \\
\text { no concreto }\end{array}$ & $\begin{array}{c}\text { Limpeza da } \\
\text { superfície } \\
\text { Realizar pintura } \\
\text { imperbeabilizante }\end{array}$ \\
\hline Mancha & $\begin{array}{c}\text { Porosidade e rugosidade do } \\
\text { Umidade }\end{array}$ & Projeto & $\begin{array}{c}\text { Aparecimento de } \\
\text { manchas escuras do } \\
\text { tipo bolor }\end{array}$ & $\begin{array}{c}\text { Limpeza da } \\
\text { superfície Realizar } \\
\text { pintura } \\
\text { imperbeabilizante }\end{array}$ \\
\hline Fissura & $\begin{array}{c}\text { Deficiência de projeto } \\
\text { Contração plástica } \\
\text { Assentamento de concreto / } \\
\text { Perda de aderência } \\
\text { Movimentação de escoramentos } \\
\text { e/ou fôrmas Corrosão das } \\
\text { armaduras }\end{array}$ & $\begin{array}{c}\text { Projeto } \\
\text { Materiais }\end{array}$ & $\begin{array}{c}\text { Deformação não- } \\
\text { prevista da } \\
\text { estrutura } \\
\text { provocando } \\
\text { abertura de fissuras } \\
\text { no concreto ou nas } \\
\text { alvenarias }\end{array}$ & $\begin{array}{c}\text { Injeção } \\
\text { Selagem } \\
\text { Ocratização } \\
\text { Cicatrização } \\
\text { Grampeamento }\end{array}$ \\
\hline
\end{tabular}

\subsection{CONCLUSÃO}

No estudo realizado, foram caracterizadas e analisadas 11 estruturas de concreto armado de uma instituição de ensino pública através da Metodologia $\mathrm{GDE} / \mathrm{UnB}$, a fim de avaliar os seus graus de deterioração. Por meio da metodologia usada foi possível fechar lacunas relativas a quais blocos necessitavam de manutenção prioritária, justificando os investimentos necessários aos 
administradores. Através deste instrumento de apoio, diversas manifestações de patologia foram identificadas e, com isso, foi possível prescrever ações corretivas à essas manifestações patológicas encontradas.

De acordo com os estudos realizados, é possível perceber que as estruturas de concreto armado estão suscetíveis a diversas manifestações patológicas, as quais suas origens estão relacionadas principalmente a fase de projeto e de execução das obras.

Apesar da instituição de ensino apresentar poucos anos de uso, foi possível obter, com as vistorias e estudos realizados em cada um de seus blocos, o total de 2 níveis altos de deterioração global, 7 médios e 2 baixos. Com isso, o nível de deterioração geral da universidade é classificado como médio.

Mesmo apresentando um nível médio, a instituição possui pouca patologia estruturais com grande recorrência, sendo estas relacionadas principalmente ao desempenho dos elementos estruturais nos aspectos da funcionalidade (deformações) e estética (manchas, bolores e infiltrações). Além disso, devido ao fato de ser uma instituição implantada recentemente, com apenas 9 anos, as manutenções que deverão ser realizadas terão baixo custo, se realizadas no período correto.

As principais manifestações patológicas das estruturas de concreto armado encontradas, usando a Metodologia GDE/UnB, foram: manchas $(29,0 \%)$; umidades $(28,5 \%)$; fissuras $(25,5 \%)$ e outras patologia (17\%), as quais incluem flechas, eflorescências, carbonatações, corrosões, cobrimentos insuficientes e segregações.

Essas ocorrências aconteceram nos diversos elementos estruturais, distribuído em cerca de 48,0\% nas lajes, $25,5 \%$ nas vigas, $25 \%$ nos pilares e $1,5 \%$ nos demais elementos estruturais.

À vista disso, é notório a necessidade da realização de manutenções em períodos pré-estabelecidos, a fim de obter uma relação dos custos e dos níveis de deterioração das estruturas o menor possível.

\section{AGRADECIMENTOS}

Os autores agradecem a Universidade Tecnológica Federal do Paraná (UTFPR), pela cessão dos laboratórios, espaço e outros.

\section{REFERENCIAS}

Associação Brasileira de Normas Técnicas (2003). NBR 6118 - Projeto de estruturas de concreto - Procedimento. Rio de Janeiro.

Associação Brasileira de Normas Técnicas (2014). NBR 6118 - Projeto de estruturas de concreto - Procedimento. Rio de Janeiro.

Bordun, R. F. “Manifestações patológicas em estruturas de concreto armado - Um estudo de caso (Bloco Administrativo da UTFPR - Pato Branco)". 96 p. Trabalho de Conclusão de Curso (Bacharel em Engenharia Civil.) - Universidade Tecnológica Federal do Paraná, Pato Branco - PR, 2014. Orientador: Prof. Dr. Mario Arlindo Paz Irrigaray. 2014.

CEB. CEB - FIP Model Code 90 (MC - 90) - Final Draft. Bulletin d'Information Nº. 203, 1991.

Fonseca, R.P. "A estrutura do Instituto Central de Ciências: Aspectos históricos, científicos e tecnológicos de projeto, execução, intervenções e propostas de manutenção". Dissertação de Mestrado em Estruturas e Construção Civil, Publicação E.DM - 006 A/07, Departamento de Engenharia Civil e Ambiental, Universidade de Brasília. Brasília, DF. 2007, 213p. Disponível em: 
$<$ http://www.pecc.unb.br/wp-content/uploads/dissertacoes/M07-6A-Regis-da-Fonseca.pdf $>$. Acesso em 20 mar. 2021.

Mazer, W. "Patologia, recuperação e reforço de estruturas de concreto”. Curitiba. UTFPR, 2008.

Medeiros, Marcelo Henrique Farias de; ANDRADE, Jairo José de Oliveira; Helene, Paulo. Durabilidade e vida útil das estruturas de concreto. In. ISAIAS, Geraldo (Ed.). Concreto: ciência e tecnologia, v. 1. São Paulo: IBRACON, 2011.

Mehta, P. Kumar; MONTEIRO, Paulo J. M. "Estrutura propriedades e materiais". São Paulo: Pini, 1994 